\title{
Ozone-induced respiratory symptoms: exposure-response models and association with lung function
}

\author{
W.F. McDonnell*, P.W. Stewart**, M.V. Smith ${ }^{+}$, W.K. Pan**, J. Pan**
}

\begin{abstract}
Ozone-induced respiratory symptoms: exposure-response models and association with lung function. W.F. McDonnell. P.W. Stewart, M.V. Smith, W.K. Pan, J. Pan. (C)ERS Journals Ltd 1999.

ABSTRACT: Ozone-induced respiratory symptoms are known to be functions of concentration, minute ventilation, and duration of exposure. The purposes of this study were to identify an exposure-response model for symptoms, to determine whether response was related to age, and to assess the relationships between symptom and lung function responses to ozone.

Four hundred and eighty-five healthy male volunteers (ages 18-35 yrs) were exposed to one of six ozone concentrations at one of three activity levels for $2 \mathrm{~h}$. Symptoms and forced expiratory volume in one second (FEV1) were assessed at the end of 1 and $2 \mathrm{~h}$. The exposure and response data were fitted by a nonlinear exposure-response model previously found to describe FEV1 response.

The proportion of individuals experiencing moderate or severe cough, shortness of breath, and pain on deep inspiration were accurately described as functions of concentration, minute ventilation, and time. Response was inversely related to age for shortness of breath $(p=0.0001)$, pain on deep inspiration $(p=0.0002)$, and cough $(p=$ 0.0013). Controlling for exposure differences, symptom responses were significantly but weakly (correlation coefficient $0.30-0.41$ ) related to the FEV1 response.

In conclusion, the exposure-response model did accurately predict symptoms, response was inversely related to age.

Eur Respir J 1999; 14: 845-853.
\end{abstract}

Acute reductions in lung function and the induction of respiratory symptoms including cough, shortness of breath, and pain on deep inspiration are known to occur following short-term exposure to the levels of ozone found in ambient air [1-7]. The magnitudes of these respiratory symptoms and lung function decrements are known to be functions of ozone concentration (C), minute ventilation during exposure $\left(V^{\prime} \mathrm{E}\right)$, and duration $(\mathrm{T})$ of exposure [112]. The authors have recently identified a two-compartment model which, for studies at constant $\mathrm{C}$ and $V^{\prime} \mathrm{E}$, accurately describes the magnitude of the forced expiratory volume in one second (FEV1) decrement as a function of these exposure variables and the age of the individual [11]. The model has the following exposureresponse (E-R) characteristics which are consistent with the majority of observations reported in the literature for FEV1:1) response increases monotonically with increasing $\mathrm{C}, V^{\prime} \mathrm{E}$, and $\mathrm{T}$ [1-12]; 2) Response is nonlinear in all three exposure variables [1,3-11]; 3) At high levels of C and $V^{\prime} \mathrm{E}$, a maximal response is approached $\left.[1,3] ; 4\right)$ With increasing $\mathrm{T}$, response reaches a plateau, the magnitude of which is a function of exposure rate $\left(\mathrm{C} \times V^{\prime} \mathrm{E}\right)[9,10,13]$; 5) Response in adults decreases with increasing age [11, 14, 15].

In its more general form, this model also allows for recovery of the lung function following cessation or reduction of exposure and is able to predict response under conditions of changing $\mathrm{C}$ and $V^{\prime} \mathrm{E}$. The model does not account for the phenomenon often referred to as "adaptation" [16].
There is evidence that some $[1-3,6]$, and it is reasonable to conjecture that others, of these same E-R characteristics also apply to the incidence and severity of ozone-induced respiratory symptoms. This has not been tested, however, and predictive models have not been previously developed for respiratory symptoms.

Reports from the literature indicate that otherwise similar persons may differ markedly in the magnitudes of their symptom and lung function responses to a given ozone exposure $[1,16]$. These differences in magnitude of response have been observed to be reproducible for up to 1 $\mathrm{yr}$ for the lung function changes, as well as for the symptoms; cough and shortness of breath, which suggests that intrinsic differences in responsiveness to ozone exist among individuals $[17,18]$. It is not clear however to what extent symptom responsiveness is related to lung function responsiveness within a person. The correlations between magnitudes of lung function and symptom responses have been variably reported as ranging from strong $[6,19]$ to weak [20].

The ultimate goal of the current line of investigation is to fully characterize the relationship between ozone exposure and the resulting symptom and lung function effects, so that health risks of ambient ozone air pollution and any benefits of improved air quality can be quantified. Accomplishment of this goal will ideally require four steps: 1) identification of a model form which accurately describes response as a function of $\mathrm{C}, V^{\prime} \mathrm{E}, \mathrm{T}$, and personal characteristics such as age; 2) development of appropriate statistical techniques for estimation of model parameters; 3 ) 
estimation of model parameters from representative data set which include the relevant range of exposure conditions and personal characteristics; and 4) validation of model predictions under conditions of ambient exposure. The specific purposes of this current study were: 1) to determine whether a previously identified E-R model for lung function changes could be modified to accurately describe the proportion of individuals experiencing respiratory symptoms as functions of $\mathrm{C}, V^{\prime} \mathrm{E}$, and $\mathrm{T}$ on a data set of $2 \mathrm{~h}$ exposures with essentially steady-state exposure conditions; 2) to determine whether the symptom component of the ozone response is related to age; and 3) to characterize the degree to which the magnitudes of symptom and FEV1 responses are related in individuals. The model forms identified here may ultimately be useful for characterizing the relationships between development of respiratory symptoms and ambient ozone exposure for the purposes of risk assessment and standard setting.

\section{Methods}

\section{Study subjects}

The exposure and response data which this study modelled were generated in a series of eight experimental chamber exposure studies conducted at the U.S. Environmental Protection Agency Clinical Research Facility in Chapel Hill, NC, USA over the period 1980-1993 [1, 7, 21-23]. The subjects were 485 nonsmoking, healthy, Caucasian males, aged 18-36 yrs. Potential subjects were excluded if they had any history of asthma, chronic disease, symptoms of an acute respiratory infection within 4 weeks of exposure, or for current medication usage. All studies were approved by the Committee on the Protection of the Rights of Human Subjects of the University of North Carolina School of Medicine, and all volunteers read and signed a statement of informed consent for the study in which they participated.

\section{Study design}

The details of the exposure protocol which was nearly identical for all studies are documented in the original manuscripts. Briefly, for each study, each subject was exposed for $2 \mathrm{hrs}$ on one occasion to one of six ozone concentrations $(0.0,0.12,0.18,0.24,0.30$, or 0.40 parts per million (ppm)) at one nominal level of exercise. In the event that a subject participated in more than one study or if they received a clean air exposure in addition to an ozone exposure, only data from the first exposure in the facility were used for the current analysis with one exception. For that excepted study, in which each participant received both air and $0.40 \mathrm{ppm}$ ozone exposures, the air data from every third subject were used and the ozone data from the other two-thirds were used in order to take advantage of the greater amount of information inherent in an ozone exposure relative to an air exposure. The total numbers of subjects in the final data sat were $102(0.0 \mathrm{ppm}), 56(0.12)$, 118 (0.18), 54 (0.24), 50 (0.30), and $105(0.40)$.

Prior to exposure, at the end of the first hour, and at the end of the second hour of exposure, individuals ranked the symptoms "cough", "shortness of breath", and "pain on deep inspiration" as being currently "none", "mild", "moderate", or "severe". FEV1 was measured in triplicate at the same three times. Using the largest FEV1 of the three trials for each session, the per cent decrement $(100 \% \times$ (prepost)/pre) in FEV1 $(\triangle \mathrm{FEV} 1)$ was calculated at the end of the first and second hours of exposure.

During the 2-h exposures individuals alternated $15 \mathrm{~min}$ periods of rest with 15 min periods of an activity which varied from rest in some studies to moderate treadmill exercise in others to heavy treadmill exercise in yet other studies. For each exposure the level of activity was essentially constant across all four exercise periods. $V^{\prime} \mathrm{E}$ was measured for $2 \mathrm{~min}$ during the latter part of each of the four activity periods. Because of the difficulty in obtaining an accurate estimate of true resting $V^{\prime} \mathrm{E}$, a $V^{\prime} \mathrm{E}$ of $5 \mathrm{~L} \cdot \mathrm{min}^{-1} \times$ body surface area (BSA) in $\mathrm{m}^{2}$ was assigned to each 15 min period in which a participant was resting. Because the frequency of alternation between rest and activity was short $(15 \mathrm{~min})$ relative to the observed time constant $(1.45$ h) of the model for FEV1 responses [11] and because activity level and hence $V^{\prime} \mathrm{E}$ were nominally constant for each subject across all four exercise periods, each $2 \mathrm{~h}$ exposure was treated as being of constant activity. Timeweighted averages of $V^{\prime} E$ were used for the first hour (four 15-min periods) and for both hours (eight periods) as predictors of the 1-h and 2-h responses, respectively. These values will appear smaller than those reported in the original manuscripts for which only $V^{\prime} \mathrm{E}$ during activity was reported.

The details of assessment of symptoms, FEV1, and $V^{\prime} \mathrm{E}$, and of the production of ozone and maintenance of chamber conditions is provided in detail in the original manuscripts.

\section{Model specification}

The ER model which has been used successfully to predict FEV1 responses as a frequency $(f)\left(\mathrm{C}, V^{\prime} \mathrm{E}, \mathrm{T}\right.$, age $)$ for the age range 18-36 yrs, has been previously described in detail [11]. Briefly, it can be conceptualized as consisting of two compartments (fig. 1), in the first of which the concentration of active substance $\mathrm{X}([\mathrm{X}])$ increase as a function of the rate at which ozone is inhaled $\left(\mathrm{C} \times V^{\prime} \mathrm{E}\right)$ and decreases as a function of $[\mathrm{X}]$ in the compartment which is assumed to be of unknown but fixed volume $(V)$. This model assumes that fractional uptake of ozone at the active site and rates of conversion of ozone to $\mathrm{X}$ are time invariant. In the second compartment, described by the three parameter logistic functions [24], the decrement in FEV1 is assumed to increase as a sigmoid-shaped function of $[\mathrm{X}]$ in compartment 1 with age modifying the relationship between $[\mathrm{X}]$ and FEV1. The mathematical statement of this model form comprises equations 1 and 2 where $\gamma \mathrm{n}$ and a are unknown coefficients (see below). The exponent of $V^{\prime} \mathrm{E}$ allows $\mathrm{C}$ and $V^{\prime} \mathrm{E}$ to contribute differentially to uptake of ozone. Note that this model form satisfies all the known E-R characteristics listed in the introduction, and it allows for changing patterns of $\mathrm{C}$ and $V^{\prime} \mathrm{E}$ and for recovery.

$$
\begin{gathered}
\mathrm{d}[\mathrm{X}] / \mathrm{dt}=\frac{\mathrm{c}(\mathrm{t}) \times\left(V^{\prime} \mathrm{E}(\mathrm{t})\right)^{\gamma_{4}}}{V}-\mathrm{a}[\mathrm{X}] \\
\Delta \mathrm{FEV}_{1}=\frac{\gamma_{1}\left(1+\gamma_{2} \text { Age }\right)}{1+\gamma_{5} \mathrm{e}^{-\gamma_{3}[\mathrm{X}]}}
\end{gathered}
$$

Although this model was developed for a continuous outcome variable (FEV1), it was hypothesized that the 
Compartment 1

Compartment 2

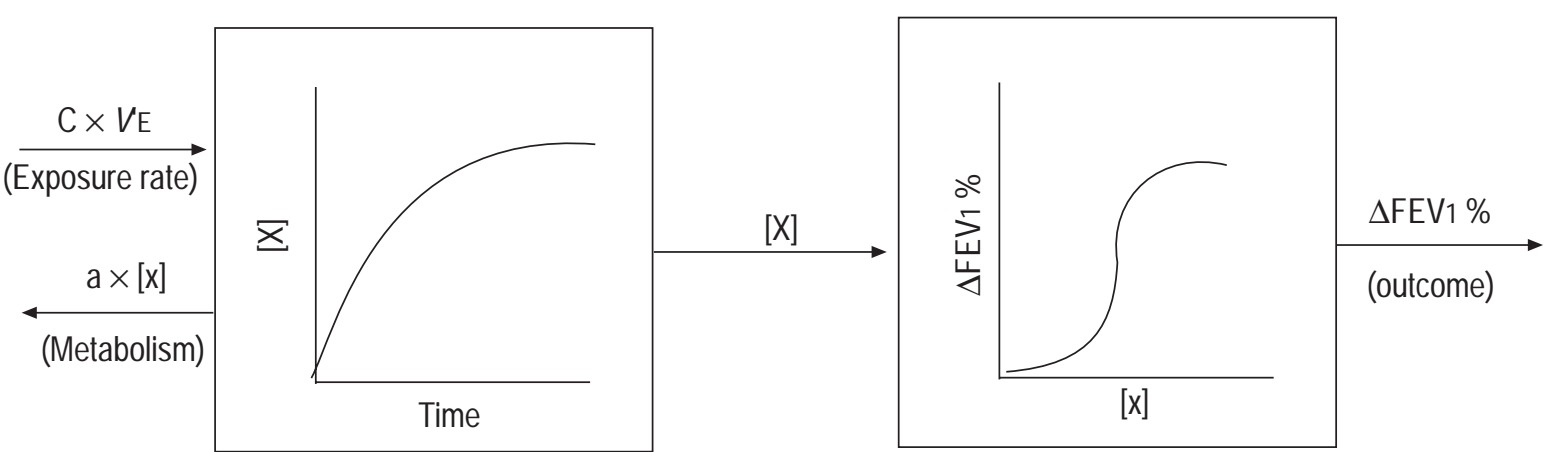

Fig. 1. - A two compartment model of the per cent decrement in forced expiratory volume in one second (FEV1) as a function of ozone concentration (c), minute ventilation $\left(V^{\prime} \mathrm{E}\right)$, and duration of exposure. a: unknown coefficient; [X]: concentration of active substance X.

model form would also be useful for describing dichotomous outcome variables such as symptoms. Because parameter estimates will depend to some extent upon the choice of "cutpoints" for dichotomizing outcomes, physiological interpretation of the parameters, where possible, may be less appropriate than for the case of a continuous outcome variable.

Symptoms were measured as none mild moderate, or severe, and for each symptom the authors utilized the binary response variable $\mathrm{Yi}\left(\mathrm{C}, V^{\mathrm{T}} \mathrm{E}, \mathrm{T}\right)$ defined for the $\mathrm{i}^{\text {th }}$ individual for given $\mathrm{C}, V^{\prime} \mathrm{E}$, and $\mathrm{T}$, as 0 for the presence of no or mild symptoms and 1 for the presence of moderate or severe symptoms. The authors also refit the FEV1 data using a dichotomous outcome with changes from baseline of $<15 \%$ represented by 0 and those $\geq 15 \%$ represented by 1. These symptom and FEV1 cut points were chosen to be severe enough that few individuals would experience these changes due to exercise or measurement error alone, yet not so extreme that only a small proportion of individuals would experience them at high exposures.

Use of a dichotomous outcome variable changes the interpretation of compartment 2 somewhat with the output now representing the probability $\mathrm{Pi}\left(\mathrm{C}, V^{\prime} \mathrm{E}, \mathrm{T}\right)$ that a given individual will develop the outcome of interest given $\mathrm{C}$, $V^{\prime} \mathrm{E}$, and $\mathrm{T}$. In this model the authors allowed this probability to vary among individuals. The average of the probabilities taken over all individuals is $\mathrm{P}\left(\mathrm{C}, V^{\prime} \mathrm{E}, \mathrm{T}\right)$ which may be interpreted as the probability that a randomly selected individual will experience the outcome of interest and also interpreted as the proportion of the population expected to experience the outcome of interest given $\mathrm{C}, V^{\prime} \mathrm{E}$, and T. This proportion is the focus of this study and is modelled as a function of exposure and age (equation 3 ). Equation 3 is an equivalent form of the model defined by equation 1 and 2 for the special case in which $\mathrm{C}$ and $V^{\prime} \mathrm{E}$ are constant and $[\mathrm{X}]=0$ at $\mathrm{T}=0$, and it is the model form for which parameters were actually estimated.

$$
\mathrm{P}\left(\mathrm{C}, V^{\prime} \mathrm{E}, \mathrm{T}\right)=\frac{\beta_{1}\left(1+\beta_{2} \text { Age }\right)}{1+\mathrm{e}^{-\beta 3}\left(\mathrm{C} V^{\prime} \mathrm{E}{ }^{\beta 4}\left(1-\mathrm{e}^{-\beta 6 \mathrm{~T}}\right)^{-\beta 5}\right.}
$$

The estimated values of the coefficients which were defined in equations 1 and 2 can be derived from the parameter estimates in equation 3 by the following transformations: $\gamma_{1}=\beta_{1}, \gamma_{2}=\beta_{2}, \gamma_{3} / V=\beta_{3} \beta_{6}, \gamma_{4}=\beta_{4}, \gamma_{5}=\mathrm{e}^{-\beta_{5}}$, and $\mathrm{a}=\beta_{6}$.
The complete model from which the parameters were estimated includes specification of the mean response (equation 3 ) and specification of the variance, covariance, and the correlation among the repeated measures which has been previously described [25]. The only difference between the model fit to these symptom data and that previously published for dichotomous FEV1 response is the better fitting expression for the mean response in the current paper.

\section{Statistical analysis}

Computations for estimating the model parameters from the data were performed with a SAS procedure specially designed for fitting nonlinear random-effects models for repeated measurements [26-28]. This procedure uses a strategy known as iteratively reweighted least squares to obtain parameter estimates. The statistical methods underlying the procedure's estimates of precision, confidence intervals, and tests of hypotheses are appropriate for large sample sizes. Note that all reported parameter estimates assume that age was centred around the mean age (24 yrs), that $V^{\prime}$ E was scaled by dividing by 100 , and that the predicted proportion experiencing an effect was multiplied by $100 \%$.

In order to characterize the degree of association between symptom responsiveness and lung function responsiveness within an individual, the relationships among the dichotomous outcomes described above were analysed, and the distributions of lung function response for the levels of symptom severity were also plotted. For the $2 \mathrm{~h}$ responses, two-by-two tables were constructed and prevalence ratios (PR) were calculated which were defined as the ratio of the probability of experiencing a moderate or severe symptom among those with $15 \%$ FEV1 decrements to the probability of experiencing a moderate or severe symptom among those without $15 \%$ FEV1 decrements. The crude PR was calculated for each symptom for the $2 \mathrm{~h}$ responses of the entire dataset. As a means of controlling for the independent effects of exposure upon the outcomes, the data were also stratified into quintiles based upon exposure rate $\left(\mathrm{C} \times V^{\prime} \mathrm{E}\right)$, and prevalence ratios were calculated for each of five strata. The Mantel-Haenszel estimator of the common prevalence ratio (mPR) for all strata which do not contain cells with zero observations was calculated as an estimate of the overall relationship among the different 
outcomes controlling for exposure differences [29]. Homogeneity of the stratum specific estimates for strata which did not contain a zero in any cell was assessed by the Breslow Day test [29].

\section{Results}

A total of 485 individuals were exposed once to ozone. The characteristics of these participants are presented in table 1 and are stratified by level of $V^{\prime} \mathrm{E}$ averaged over the entire $2 \mathrm{~h}$ exposure. All of the 485 volunteers provided data for FEV1, 453 for cough, 452 for pain upon deep inspiration, and 453 for shortness of breath. Of these, data were excluded from analysis for cough ( $\mathrm{n}=40$ subjects), pain on deep inspiration $(\mathrm{n}=13)$, and shortness of breath $(n=20)$ for volunteers who reported a mild, moderate, or severe symptom prior to exposure (i.e., at baseline). In table 2, the percentages of individuals experiencing a response (moderate or severe symptom or $15 \%$ FEV 1 decrement) and the number of individuals contributing data are presented stratified by ozone concentration, duration, and activity level. For the clean air exposures, only one individual reported a moderate or severe symptom, and none experienced a $15 \%$ FEV 1 decrement. For the resting exposures, symptoms and lung function changes were noted only at the highest ozone concentration. The percentage of individuals experiencing the effect of interest generally increased with increasing $\mathrm{C}, V^{\prime} \mathrm{E}$, and $\mathrm{T}$. For the second hour of exposure, the percentages appeared to approach a plateau with increasing level of $\mathrm{C}$ and $V^{\prime} \mathrm{E}$.

Plots of the predicted (solid lines) and observed (points) data with $95 \%$ confidence intervals for proportions of individuals experiencing the effects of interest are presented in figure 2 . In general, the predicted values closely approximate the observed values at all levels of the independent variables indicating that the model accurately describes the data for each of the symptoms and for a $15 \%$ FEV 1 decrement across the range of available data.

The estimated model regression coefficients (based upon equation 3 ) for each of the outcomes are presented in table 3 . The numerator of equation 3 represents the maximal percentage of individuals who are predicted to ex-

Table 1. - Characteristics of participants and exposures

\begin{tabular}{|c|c|c|c|}
\hline & \multicolumn{3}{|c|}{ Exercise Level* } \\
\hline & Rest & Moderate & Heavy \\
\hline $\mathrm{n}$ & 78 & 172 & 235 \\
\hline $\mathrm{BSA} \mathrm{m}^{2}$ & $\begin{array}{c}2.02 \pm 0.15 \\
(1.63-2.67)\end{array}$ & $\begin{array}{c}1.86 \pm 0.12 \\
(1.59-2.20)\end{array}$ & $\begin{array}{c}1.99 \pm 0.13 \\
(1.67-2.50)\end{array}$ \\
\hline Age yrs & $\begin{array}{c}25.1 \pm 3.6 \\
(19.7-34.7)\end{array}$ & $\begin{array}{c}24.1 \pm 4.2 \\
(18.2-35.9)\end{array}$ & $\begin{array}{c}23.3 \pm 3.2 \\
(18.1-32.3)\end{array}$ \\
\hline$V^{\prime} \mathrm{E}, \mathrm{L} \cdot \mathrm{min}^{-1}$ & $\begin{array}{c}10.1 \pm 0.8 \\
(8.1-13.4)\end{array}$ & $\begin{array}{c}30.4 \pm 3.3 \\
(21.5-34.9)\end{array}$ & $\begin{array}{c}39.1 \pm 2.9 \\
(35.0-50.3)\end{array}$ \\
\hline $\begin{array}{l}V^{\prime} \mathrm{E} / \mathrm{BSA} \\
\mathrm{L} \cdot \mathrm{min}^{-1} \cdot \mathrm{m}^{2}\end{array}$ & $\begin{array}{c}5.0 \pm 0.0 \\
(5-5)\end{array}$ & $\begin{array}{c}16.4 \pm 1.9 \\
(11.6-20.7)\end{array}$ & $\begin{array}{c}19.7 \pm 1.4 \\
(15.9-24.1)\end{array}$ \\
\hline
\end{tabular}

Data are presented as mean \pm SD with range in parentheses. *: rest, minute ventilation $\left(V^{\prime} \mathrm{E}\right)=8.1-13.4 \mathrm{~L} \cdot \mathrm{min}^{-1}$, moderate, $V^{\prime} \mathrm{E}$ $=21.5-34.9 \mathrm{~L} \cdot \mathrm{min}^{-1}$, heavy, $V^{\prime} \mathrm{E}=35.0-50.3 \mathrm{~L} \cdot \mathrm{min}^{-1}$. BSA: body surface area. Minute ventilation was averaged over the four periods of exercise during exposure averaged with $5 \times$ BSA to account for the rest periods.
Table 2. - Percentage of participants experiencing moderate or severe symptoms or a $15 \%$ decrement in forced expiratory volume in one second (FEV 1$)$ during ozone exposure

\begin{tabular}{|c|c|c|c|c|c|c|}
\hline \multirow{3}{*}{$\begin{array}{l}\text { Ozone } \\
\text { ppm }\end{array}$} & \multicolumn{6}{|c|}{ Activity Level* } \\
\hline & \multicolumn{2}{|c|}{ Rest } & \multicolumn{2}{|c|}{ Moderate } & \multicolumn{2}{|c|}{ Heavy } \\
\hline & $1 \mathrm{~h}$ & $2 \mathrm{~h}$ & $1 \mathrm{~h}$ & $2 \mathrm{~h}$ & $1 \mathrm{~h}$ & $2 \mathrm{~h}$ \\
\hline \multicolumn{7}{|l|}{ Cough } \\
\hline 0.0 & $0(9)$ & $0(9)$ & $0(25)$ & $0(24)$ & $0(39)$ & $0(44)$ \\
\hline 0.12 & $0(1)$ & 0 (1) & $0(23)$ & $5(22)$ & $0(24)$ & $8(24)$ \\
\hline 0.18 & $0(12)$ & $0(12)$ & $0(30)$ & $10(30)$ & $8(62)$ & $25(60)$ \\
\hline 0.24 & $0(17)$ & 0 (17) & $22(18)$ & $28(18)$ & $10(10)$ & $40(10)$ \\
\hline 0.30 & $0(12)$ & $0(12)$ & $25(20)$ & $25(20)$ & 57 (14) & $58(12)$ \\
\hline 0.40 & $0(21)$ & $0(21)$ & $27(26)$ & $40(30)$ & $42(31)$ & $55(38)$ \\
\hline
\end{tabular}

Pain on Deep Inspiration

$\begin{array}{lrrrrrr}0.0 & 0(9) & 0(9) & 0(28) & 0(27) & 2(42) & 0(47) \\ 0.12 & 0(1) & 0(1) & 0(22) & 9(23) & 0(23) & 9(22) \\ 0.18 & 0(11) & 0(12) & 0(31) & 27(30) & 8(65) & 38(65) \\ 0.24 & 0(17) & 0(17) & 9(22) & 29(21) & 15(13) & 38(13) \\ 0.30 & 0(12) & 0(12) & 24(21) & 33(21) & 31(16) & 47(15) \\ 0.40 & 0(22) & 5(22) & 29(28) & 53(32) & 45(33) & 53(38)\end{array}$

Shortness of breath

$\begin{array}{lrrrrrr}0.0 & 0(9) & 0(9) & 0(25) & 0(24) & 0(41) & 0(46) \\ 0.12 & 0(1) & 0(1) & 0(23) & 4(23) & 0(25) & 8(25) \\ 0.18 & 0(10) & 0(10) & 3(32) & 26(31) & 9(67) & 24(66) \\ 0.24 & 0(17) & 0(17) & 14(22) & 38(21) & 23(13) & 38(13) \\ 0.30 & 0(12) & 0(12) & 41(22) & 48(21) & 27(15) & 43(14) \\ 0.40 & 0(20) & 0(20) & 31(26) & 43(30) & 34(32) & 48(40)\end{array}$

$15 \% \mathrm{FEV} 1$ decrement

$\begin{array}{lllllll}0.0 & 0(13) & 0(13) & 0(30) & 0(31) & 0(58) & 0(58)\end{array}$

$\begin{array}{lllllll}0.12 & 0(1) & 0(1) & 0(28) & 0(28) & 0(27) & 0(27)\end{array}$

$\begin{array}{lllllll}0.18 & 0(13) & 0(13) & 0(32) & 3(32) & 6(72) & 31(72)\end{array}$

$\begin{array}{lllllll}0.24 & 0(17) & 0(17) & 0(22) & 14(22) & 27(15) & 40(15)\end{array}$

$\begin{array}{lllllll}0.30 & 0(12) & 0(12) & 10(21) & 23(22) & 12(16) & 50(16)\end{array}$

$\begin{array}{llllllll}0.40 & 0(22) & 5(22) & 38(37) & 57(37) & 24(46) & 46(46)\end{array}$

Data are presented as percentages with number of participants with data for that stratum in parentheses. *: rest, minute ventilation $\left(V^{\prime} \mathrm{E}\right)=8.1$ to $13.4 \mathrm{~L} \cdot \mathrm{min}^{-1}$, moderate, $V^{\prime} \mathrm{E}=21.5-34.9$ $\mathrm{L} \cdot \mathrm{min}^{-1}$, heavy, $V^{\prime} \mathrm{E}=35.0-50.3 \mathrm{~L} \cdot \mathrm{min}^{-1}$.

perience the response of interest at high exposure rates $\left(\mathrm{C} \times V^{\prime} \mathrm{E}\right)$. Because age was centred around the mean age (i.e. 24 was subtracted from actual age), $\beta_{1}$ represents the percentage of $24 \mathrm{yr}$ old individuals expected to experience the response at high exposure and ranges from 40 $50 \%$ depending upon the outcome of interest. For each increasing year of age, this maximal response is predicted to decrease by $\sim 5 \%$ of $\beta_{1}$ indicating that response is inversely related to age over the range $18-36$ yrs. This effect of age, represented by $\beta_{2}$, was significantly $<0$ for all outcomes with the exception of cough $(p$-value $=0.19)$.

The exponent of $V^{\prime} \mathrm{E}\left(\beta_{4}\right)$ was not significantly different than 1 for any of the variables indicating that the probability of developing a symptom or lung function decrement was equally sensitive to changes in $V^{\prime} \mathrm{E}$ and $\mathrm{C}$. However, for shortness of breath, $\beta_{4}$ did approach statistical significance. A sensitivity analysis in which $\beta_{4}$ was fixed at 1.0 and the model refit resulted in almost identical predictions to those generated from the parameter estimates in table 3 and illustrated in figure 2 , indicating that differences, if 


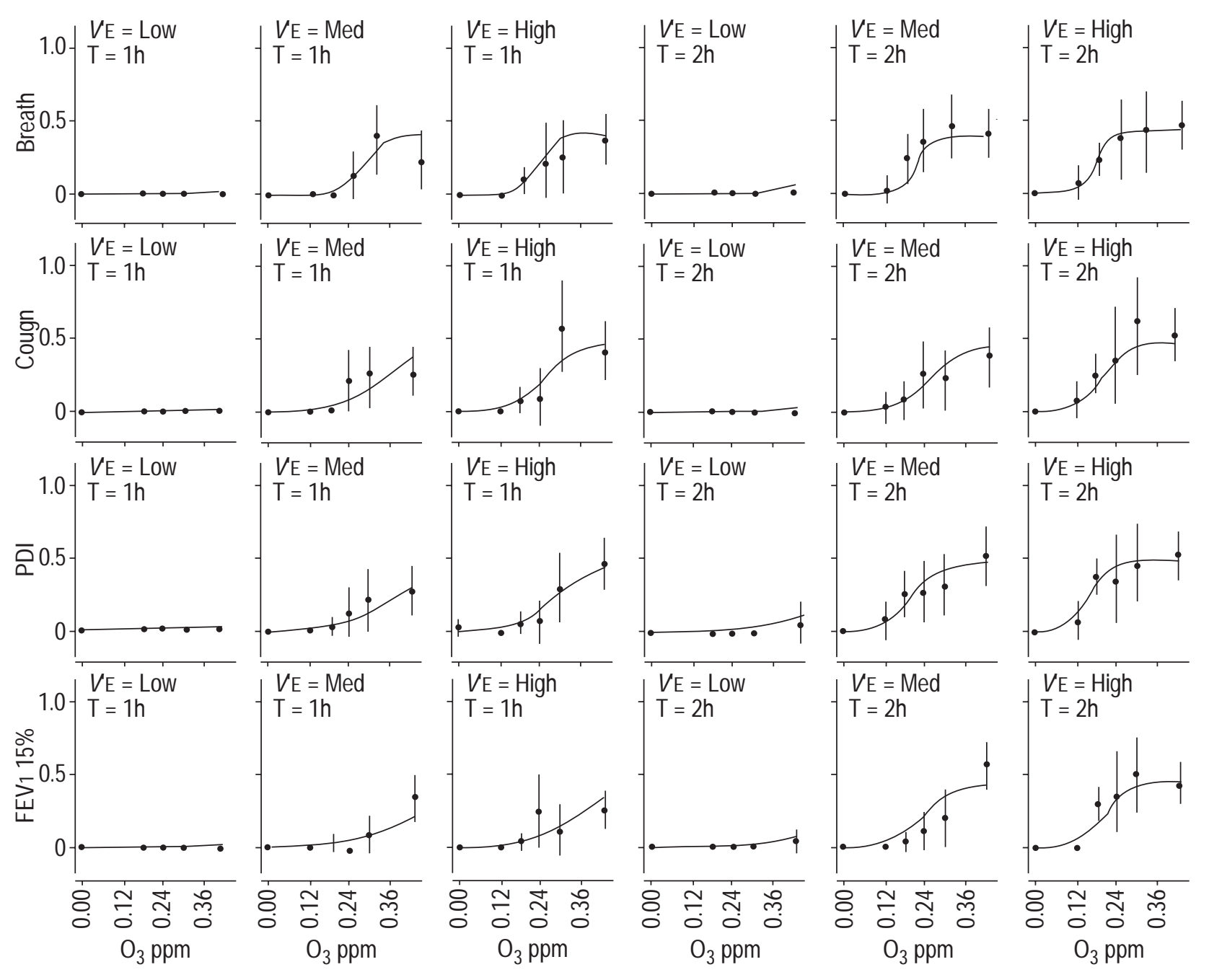

Fig. 2. - Observed (points) and predicted (lines) percentages of individuals reporting moderate or severe symptoms as a function of ozone concentration stratified on duration of exposure $(\mathrm{T})$ and level of minute ventilation $\left(V^{\prime} \mathrm{E}\right)$. Vertical bars are $95 \%$ confidence levels. Breath: "shortness of breath" symptoms; Cough: "cough" symptoms; PDI: "pain on deep inspiration" symptom; FEV1: forced expiratory volume in one second; ppm: parts per million.

any, in the sensitivity of shortness of breath to changes in $\mathrm{C}$ and $V^{\prime} \mathrm{E}$ are small. This suggests that this model can adequately describe ozone E-R characteristics without the need for the $\beta_{4}$ term.

Both the graphs of the predicted responses in figure 2 and the values of the coefficient $\beta_{6}$ (table 3 ), which represents the inverse of the time constant of compartment 1 for continuous outcome variables, suggest that the rates of development of mild or moderate pain on deep inspiration and of development of a $15 \%$ decrement in FEV1 may be longer than for cough and shortness of breath. Because $\beta_{3}$ and $\beta_{6}$ were highly correlated (r=-0.97 and -0.93$)$ for pain on deep inspiration and $15 \% \mathrm{FEV}_{1}$ decrement, however, and because parameter estimates are dependent upon the cutpoint chosen for dichotomization of the data, conclusions which can be drawn from these data about differences in time constants among the different outcomes are limited.

Table 3. - Regression coefficientS \pm SEM for models predicting the percentage of individuals experiencing moderate or severe respiratory symptoms or $15 \%$ forced expiratory volume in one second (FEV1) decrements

\begin{tabular}{lcccccc}
\hline Model & $\beta_{1}$ & $\beta_{2}$ & $\beta_{3}$ & $\beta_{4}$ & $\beta_{5}$ & $\beta_{6}$ \\
\hline Cough & $47.2 \pm 6.9$ & $-0.032 \pm 0.24$ & $79.0 \pm 19.9$ & $1.02 \pm 0.20$ & $-5.21 \pm 0.74$ & $1.23 \pm 0.25$ \\
Breath & $41.3 \pm 2.5$ & $-0.070 \pm 0.14$ & $106.2 \pm 25.2$ & $0.79 \pm 0.11$ & $-7.72 \pm 1.82$ & $1.25 \pm 0.28$ \\
PDI & $48.8 \pm 3.2$ & $-0.46 \pm 0.13$ & $264.7 \pm 228.7$ & $0.99 \pm 0.18$ & $-4.73 \pm 0.83$ & $0.18 \pm 0.17$ \\
$15 \%$ FEV1 & $45.6 \pm 3.1$ & $-0.064 \pm 0.13$ & $152.8 \pm 84.6$ & $0.84 \pm 0.15$ & $-4.87 \pm 0.76$ & $0.24 \pm 0.15$ \\
\hline
\end{tabular}

Regression coefficients correspond to those in equation 3. Breath: shortness of breath; PDI $=$ pain on deep inspiration. Note that $\beta_{1}$ is expressed as a percentage; age was centred around $24 \mathrm{yrs}$, minute ventilation $\left(V^{\prime} \mathrm{E}\right)$ was divided by $100 ; 95 \%$ confidence intervals can be approximated by the parameter estimate $+/-1.96$ sEM. Cough $n=4 b$, breath $n=433$, PDI $n=439$ and $15 \%$ FEV1 $n=485$. 
Table 4. - Crude, stratum specific, and Mantel-Haenszel adjusted prevalence ratios (PR) as a measure of association between development of moderate or severe respiratory symptoms and development of $15 \%$ forced expiratory volume in one second (FEV1) decrement

\begin{tabular}{lcccc}
\hline Sample & $\mathrm{C} \times V^{\prime} \mathrm{E} \mathrm{mL} \mathrm{O} \cdot \mathrm{min}^{-1}$ & Cough & Breath & PDI \\
\hline Unstratified $(\mathrm{n}=485)$ & $0-18.8$ & $5.24(3.64-7.56)$ & $4.34(3.09-6.10)$ & $3.80(2.76-5.23)$ \\
Stratum 1 $(\mathrm{n}=102)$ & 0 & $\mathrm{D}$ & $\mathrm{D}$ & $\mathrm{D}$ \\
Stratum 2 $(\mathrm{n}=91)$ & $0.1-4.2$ & $\mathrm{D}$ & $\mathrm{D}$ & $\mathrm{D}$ \\
Stratum 3 $(\mathrm{n}=98)$ & $4.2-6.8$ & $4.34(1.54-12.24)$ & $2.25(0.86-5.85)$ & $2.99(1.55-5.79)$ \\
Stratum 4 $(\mathrm{n}=97)$ & $6.8-10.4$ & $1.81(0.96-3.40)$ & $1.60(0.93-2.73)$ & $1.57(0.92-2.69)$ \\
Stratum 5 $(\mathrm{n}=97)$ & $10.4-18.8$ & $2.17(1.29-3.65)$ & $2.51(1.41-4.48)$ & $1.57(1.00-2.46)$ \\
Adjusted $^{+}(\mathrm{n}=292)$ & $4.2-18.8$ & $2.20(1.53-3.17)$ & $2.08(1.46-2.97)$ & $1.75(1.28-2.40)$ \\
\hline
\end{tabular}

Data are presented as range of exposure rates expressed as the product of concentration $(\mathrm{C})$ and minute ventilation $\left(V^{\prime} \mathrm{E}\right)$ for each stratum, and PR with $95 \%$ confidence intervals in parentheses. *: PR defined as the ratio of the proportion of individuals with a $15 \% \mathrm{FEV} 1$ decrement who also had a moderate or severe symptom to the proportion of those without a $15 \%$ FEV1 decrement who had a respiratory symptom. D: undefined or unstable PR estimates due to zeros in one or more cells; ${ }^{+}$: Mantel-Haenszel estimator of the common PR across the three upper strata. Breath: shortness of breath; PDI: pain on deep inspiration. Note that the first stratum contains slightly more subjects to include all with clean air exposures. Because of missing data, actual numbers for each symptom are smaller than listed

The crude or unstratified PR (table 4) which compares the proportion of those who experienced symptoms among those with and without a $15 \%$ FEV1 decrement was calculated for each symptom for the $2 \mathrm{~h}$ data of the entire dataset, and all were significantly $>1$. The crude PR of 5.24 for cough indicates that individuals who experienced a $15 \%$ FEV 1 decrement were $>5$ times as likely to experience moderate or severe cough as individuals who did not have a $15 \%$ decrement. Somewhat weaker associations were noted between FEV1 decrement and shortness of breath and pain on deep inspiration. The undefined or unstable PRs for the two lowest exposure strata (table 4) are the result of minimal effects of exposure at these levels resulting in zeros in one or more cells of the two bytwo tables. There was no significant heterogeneity among the PRs for the upper three strata for any symptom [29]. For these upper three strata the stratum-specific PRs were all uniformly less than the crude PR indicating that the crude PR overestimates the true relationship between symptom development and FEV1 change within each of these strata. For example in contrast to a crude PR of 5.24 the Mantel-Haenszel estimator of mPR for the upper three strata of 2.2 for cough indicates that, when comparing individuals with similar exposures, an individual with a $15 \% \mathrm{FEV} 1$ decrement is only twice as likely to report a moderate or severe cough as an individual with $<15 \%$ FEV1 decrement. The relationships among the three symptoms were also measured by the Mantel-Haenszel estimator of the mPR for the three upper strata. The mPR ( $95 \%$ confidence interval) of developing moderate or severe shortness of breath given moderate or severe cough was 2.85 (1.97-4.13) the mPR of developing pain on deep inspiration given cough was $1.57(1.13-2.17)$ and the $\mathrm{mPR}$ of developing pain on deep inspiration given shortness of breath was 2.13 (1.58-2.89).

In order to explore in more detail the relationships between lung function changes and symptom severity independently of how the data were dichotomized and of any dose-response effects, the authors plotted the individual data for the second hour of exposure of the quintile of participants with the highest exposures fig. 3. These individuals are on the upper plateau of their individual E-R curves in the range at which magnitude of response is no longer related to exposure level. Excluding measurement error any observed individual variability in response for this group is thus likely to reflect differences in individual responsiveness to high levels of ozone rather than differences in exposure. For the data in figure 3 the Spearman correlation coefficient between rank of symptom level and rank of FEV1 response was significantly $(\mathrm{p}<0.05)$ greater than zero for cough $(\mathrm{r}=0.39)$ shortness of breath $(\mathrm{r}=0.41)$ and pain on deep inspiration $(\mathrm{r}=0.30)$ and as symptom severity increased the mean percentage FEV1 decrement also generally increased. There remains however a large degree of variability in FEV1 response which cannot be accounted for by the level of reported respiratory symptoms and vice versa. For these same participants the Spearman correlation coefficient among symptoms was 0.52 for cough and pain on deep inspiration 0.56 for cough and shortness of breath and 0.62 for pain on deep inspiration and shortness of breath (all $\mathrm{p}<$ $0.0001)$.

\section{Discussion}

The two-compartment model which has previously been found to predict the mean FEV1 decrement [11] also adequately describes the proportion of individuals who experienced a moderate or severe respiratory symptom across the range of ozone concentrations, activity levels, and durations of exposure of the underlying studies from which the data were gathered. In its general form, the behaviour of this model is consistent with most of the known E-R characteristics for an even wider range of ozone exposure conditions including recovery and changing patterns of $\mathrm{C}$ and $V^{\prime} \mathrm{E}$. This suggests that this model form may ultimately be useful for future ozone risk assessment activities. With the possible exception of differences among the rates at which moderate or severe symptoms and 15\% FEV1 decrements developed, the E-R characteristics for all the outcomes were generally similar. As noted in the "Results section", the high correlations between $\beta_{3}$ and $\beta_{6}$ limit any conclusions which can be drawn about differences in rates of symptom development. Inclusion of data from exposures of longer duration 


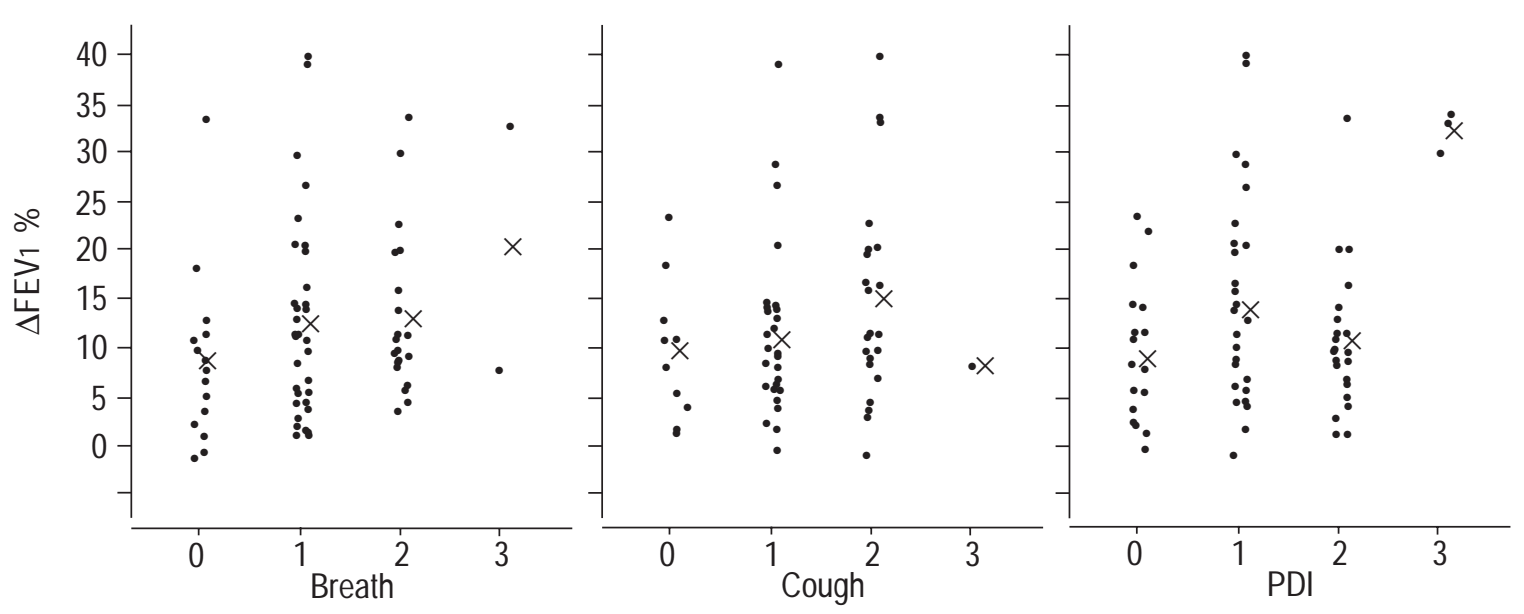

Fig. 3. - Individual per cent decrements in forced expiratory volume in one second (FEV1) for levels of coexisting a) shortness of breath (Breath), b) cough and c) pain on deep inspiration (PDI) for subjects in the highest quintile of exposure $(0=$ none, $1=$ mild, $2=$ moderate, $3=$ severe symptoms).

or with measurements of greater frequency in future modelling efforts should decrease this colinearity and help resolve this issue

Although this two-compartment model fits the data well and adequately summarizes the overall E-R relationship given the current level of resolution of the processes involved, several caveats are in order both with regard to ultimate use of this model form for risk assessment and with regard to the fidelity of the model to the underlying biological processes. The current data set to which the model is fitted only includes exposures with constant ozone concentration and activity level, response was only measured at two time points, and although the current data include a number of $\mathrm{C} \times V^{\prime} \mathrm{E}$ combinations which produce no response, no concentrations below $0.12 \mathrm{ppm}$ were included. To confirm that this model form can capture the dynamics of ozone response and recovery and describe response under conditions more relevant to the ambient situation, the model should be further tested for exposure conditions which include varying $\mathrm{C}$ and $V^{\prime} \mathrm{E}$, longer duration, and lower C. Assuming that the model form is adequate for describing response for a wide variety of exposure conditions, the next steps include parameter estimation using a representative data set which includes a wide range of relevant exposure conditions and personal characteristics followed by validation of the model predictions against data collected for ambient exposures.

With regard to the biology, the situation is certainly much more complex than illustrated by the model, involving multiple chemical reactions possible protective mechanisms including attenuation of response with recurrent exposure possibly multiple reactant species which can stimulate neural receptors, and complex neural pathways. Although the primary purpose for developing this model is prediction of population response to ambient pollutant exposure, and although physiological interpretation of parameter estimates for dischotomous outcomes are more problematic than for continuous outcomes, models such as these do provide a framework in which the current state of knowledge of ozone E-R characteristics can be summarized and from which testable hypotheses can be generated to advance knowledge and to improve the models
As has been observed for lung function changes [11] the ozone-induced symptoms, pain on deep inspiration and shortness of breath, were found to be inversely related to age for ages 18-36 yrs. These findings are consistent with the results of DRECHELER-PARKS et al. [14] who observed that volunteers $>55$ yrs of age experienced fewer ozoneinduced symptoms of cough shortness of breath and substernal discomfort than did similarly exposed younger adults. The current model, however, predicts proportions beyond the range of 0 to 1 at ages beyond those of this study indicating that over a broad age range the relationship of age with symptom response to ozone exposure is more complex than that represented by the linear age term in the model. In an attempt to better understand the effects of age, the authors tested an $\mathrm{Age}^{2}$ (yrs) term added to the numerator of equation 3 (i.e. $\beta_{1}\left(1+\beta_{2}\right.$ Age + $\left.\beta_{7} \mathrm{Age}^{2}\right)$ ). For pain on deep inspiration and shortness of breath neither the magnitude nor the significance of $\beta_{2}$ changed meaningfully from the original model and the estimate of $\beta_{7}$ was not significant. For cough, addition of the $\mathrm{Age}^{2}$ term resulted in a more negative statistically significant $(p=0.0014)$ estimate of the coefficient of the linear age term $\left(\beta_{2}\right)$ and a significant $(\mathrm{p}=0.049)$ positive estimate of $\beta_{7}$. This quadratic age term suggests that the true relationship is curvilinear even over the range of 18 36 yrs. For comparison with the results of the cough model in table 3 the coefficients and standard errors of $\beta_{1}-\beta_{7}$ (with the coefficient of $\mathrm{Age}^{2}$ being $\beta_{7}$ ) were 0.432 (0.037), -0.054 (0.017), 87.00 (26.05), 1.09 (0.21), -5.04 $(0.91), 1.08(0.30)$, and $0.006(0.003)$ respectively.

Although quantitative predictions outside of the age range of study should be made with caution, the observation that symptom response is inversely related to age for the range of 18-36 yrs does raise the question of whether individuals $<18$ yrs of age may experience even larger symptoms than those observed in these studies. In general relationship between ozone and respiratory symptoms have not been observed for children in clinical or epidemiological studies [30-32] in contrast to what may be expected from the model. The question of whether children are more or less responsive to ozone than adults remains unanswered, however, for several reasons: the 
numbers of studies of children are small relative to those of adults; in both the clinical and epidemiological studies, the levels of exposure were generally low enough that responses would have been predicted to be small and therefore difficult to detect; and questions arise about the ability of children to accurately report symptoms. The question is further complicated by the lack of knowledge of how to properly scale differences in $V^{\prime} \mathrm{E}$ for the much smaller body, long, and airway sizes of children and by the lack of precision of individual estimates of $\mathrm{C}$ and $V^{\prime} \mathrm{E}$ as a function of time for the epidemiological studies. Elucidation of the responses of children and development of methods for inclusion of children's responses in risk assessment models are areas clearly in need of further research.

It was found that the magnitudes of response to ozone for the symptoms and for FEV1 were significantly related. However, the true relationships were relatively weak (mPR $=\sim 2$ Spearman correlation $\mathrm{r}=\sim 0.35$ ) once effects of exposure differences had been accounted for. This suggests that the responses are related mechanistically to some degree but indicates that there is not a single factor (such as level of antioxidant defence) which is responsible for the observed individual differences in ozone responsiveness across the spectrum of symptom and lung function responses. Rather it is evident from figure 3 that it is quite common for a person exposed to a high concentration of ozone to have a large change in FEV1 while experiencing no or mild symptoms. Until the mechanisms of these responses are understood in more detail, it is difficult to speculate about the genesis of the differences in levels of responsiveness for the various endpoints. The observed results are consistent with those of HAYEs et al. [20] who analysed studies from three different laboratories, and found that for exposure to single ozone concentrations, magnitude of symptom response was only weakly to moderately correlated with FEV1 response. On the other hand, FolinsBEE et al. [6] found a rather strong relationship of FEV1 change with discomfort on taking a deep breath but not with cough for a group of 12 subjects exposed to $0.12 \mathrm{ppm}$ ozone for $6.6 \mathrm{~h}$. In an analysis of data from multiple studies, OSTRO and LIPSETT [19] observed a strong relationship between probability of developing respiratory symptoms and experiencing lung function changes over a large range of exposure conditions However, in that analysis, adjustments for differences in ozone exposure were not made, although exposure was noted to be a strong confounder of the symptom-lung function relationship. This is consistent with the current observation of a relatively strong crude PR which was primarily due to confounding by exposure differences.

In summary, the authors have demonstrated that the exposure-response model presented, accurately describes the probability of experiencing moderate or severe ozoneinduced symptom responses as a function of concentration, minute ventilation, and duration of exposure for $2 \mathrm{~h}$ exposures. It was also observed that the probability of developing the symptoms cough, pain on deep inspiration, and shortness of breath were inversely related to age for the range 18-36 yrs. Parameter estimation and further model validation should be undertaken using data from a broader range of exposure conditions and ages, and model predictions should ultimately be compared with responses due to ambient exposure.
Individual differences in response to ozone were evident for symptoms and lung function and after controlling for confounding by differences in exposure, the relationships of the magnitude of response among the symptom and lung function changes were relatively weak.

Acknowledgements. The authors thank their colleagues L. Folinsbee, D. Horstman. H. Kehrl, and E. Seal for their roles in the individual studies from which these data were collected; $M$. Eads for data management; S. Abdul-Salaam and P. DeWitt for technical support; S. Butler for graphics support; and the volunteers for their participation in these studies. Disclaimer: The information in this document has been subjected to review by the National Health and Environmental Effects Research Laboratory and approved for publication. Approval does not signify that the contents reflect the views of the Agency, nor does mention of trade names or commercial products constitute endorsement or recommendation for use.

\section{References}

1. McDonnell WF, Horstman DH, Hazucha MJ, et al. Pulmonary effects of ozone exposure during exercise: doseresponse characteristics. J Appl Physiol:Respirat Environ Exercise Physiol 1983; 54: 1345-1352.

2. Folinsbee LJ, Drinkwater BL, Bedi JF, Horvath SM. The influence of exercise on the pulmonary function changes due to low concentrations of ozone. In: Folinsbee LJ, Wagner JA, Borgia JF, Drinkwater BL, Gliner JA, Bedi JF, eds. Environmental Stress. Academic Press, New York, 1978; 125-145.

3. Folinsbee LJ, McDonnell WF, Horstman DH. Pulmonary function and symptom responses after 6.6 hour exposure to $0.12 \mathrm{ppm}$ ozone. J Air Pollut Control Assn 1988; 38: 28-35.

4. Kulle TJ, Sauder LR, Hebel JR, Chatham MD. Ozone response relationships in healthy nonsmokers. Am Rev Respir Dis 1985; 132: 36-41.

5. Avol EL, Linn WS, Venet TG, Shamoo DA, Hackney JD. Comparative respiratory effects of ozone and ambient oxidant pollution exposure during heavy exercise. $J$ Air Pollut Control Assoc 1984; 34: 804-809.

6. Hazucha MJ. Relationship between ozone exposure and pulmonary function changes. J Appl Physiol 1987; 62: 1671-1680.

7. Seal E, McDonnell WF, House DE, et al. The pulmonary response of white and black adults to six concentrations of ozone. Am Rev Respir Dis 1993; 147: 804-810.

8. Silverman F, Folinsbee LJ, Barnard J, Shephard RJ. Pulmonary function changes in ozone-interaction of concentration and ventilation. J Appl Physiol 1976; 41: 859-864.

9. Hazucha MJ, Folinsbee LJ, Seal E. Effects of steady-state and variable ozone concentration profiles on pulmonary function. Am Rev Respir Dis 1992; 146: 1487-1493.

10. McDonnell WF, Smith MV. Description of acute ozone response as a function of exposure rate and total inhaled dose. J Appl Physiol 1994; 76: 2776-2784.

11. McDonnell WF, Stewart PW, Andreoni S, et al. Prediction of ozone-induced FEV1 changes: effects of concentration, duration and ventilation. Am J Respir Crit Care Med 1997; 156: 715-722. 
12. Adams WC, Savin WM, Christo AK. Detection of ozone toxicity during continuous exercise via the effective dose concept. J Appl Physiol: Respirat Environ Exercise Physiol 1981; 51: 415-422.

13. Horstman DH, Ball BA, Brown J, Gerrity T, Folinsbee LJ. Comparison of pulmonary responses of asthmatic and nonasthmatic subjects performing light exercise while exposed to a low level of ozone. Toxicol Ind Health 1995; 11: $369-385$.

14. Drechsler-Parks DM, Bedi JF, Horvath SM. Pulmonary function responses of older men and women to ozone exposure. Exp Gerontol 1987; 22: 91-101.

15. Seal E, McDonnell WF, House DE. Effects of age, socioeconomic status, and menstrual cycle on pulmonary response to ozone. Arch Env Health 1996; 51: 132-137.

16. Horvath SM, Gliner JA, Folinsbee LJ. Adaptation to ozone: duration of effect. Am Rev Respir Dis 1981; 123: 496-499.

17. McDonnell WF, Horstman DH, Abdul-Salaam S, House DE. Reproducibility of individual responses to ozone exposure. Am Rev Respir Dis 1985; 131: 36-40.

18. Gliner JA, Horvath SM, Folinsbee LJ. Preexposure to low ozone concentrations does not diminish the pulmonary function response on exposure to higher ozone concentrations. Am Rev Respir Dis 1983; 127: 51-55.

19. Ostro BD, Lipsett MJ. Predicting respiratory morbidity from pulmonary function tests: a reanalysis of ozone chamber studies. J Air Pollut Control Assn 1989; 39: 1313-1318.

20. Hayes SR, Moezzi M, Wallsten TS, Winkler RL. An analysis of symptom and lung function data from several human controlled ozone exposure studies. Draft Final Report for U.S. EPA contract 69-02-4314, San Rafael, CA, Systems Applications Inc, 1987; 28-45.

21. McDonnell WF, Horstman DH, Abdul-Salaam S, Raggio LJ, Green JA. The respiratory responses of subjects with allergic rhinitis to ozone exposure and their relationship to nonspecific airway reactivity. Toxicol Ind Health 1987; 3 : 507-517.

22. Kehrl HR, Vincent LM, Kowalski RJ, et al. Ozone exposure increases respiratory epithelial permeability in humans. Am Rev Respir Dis 1987; 135: 1124-1128.

23. Koren HS, Devlin RB, Graham DE, et al. Ozone-induced inflammation in the lower airways of human subjects. Am Rev Respir Dis 1989; 139: 407-415.

24. Seber GAF, Wild CJ. Nonlinear Regression. New York, John Wiley \& Sons, 1987.

25. McDonnell WF, Stewart PW, Andreoni S, Smith MV. Proportion of moderately exercising individuals responding to low-level, multi-hour ozone exposure. Am J Respir Crit Care Med 1995; 152: 589-596.

26. Vonesh EF, Carter RL. Mixed-effects nonlinear regression for unbalanced repeated measures. Biometrics 1992; 48: $1-18$.

27. Vonesh EF. MIXNLIN: A SAS procedure for nonlinear mixed-effects models. Technical Report TR92M-0300, Applied Statistics Center, Round Lake, I1, Baxter Healthcare Corp, 1992.

28. Vonesh EF. Nonlinear models for the analysis of longitudinal data. Statist Med 1992; 11: 1929-1954.

29. Stokes ME, Davis CS, Koch GG. Categorical data analysis using the SAS system, Cary, NC: SAS Institute Inc, 1995; 51-53.

30. Hoek G, Brunekreef B. Effect of photochemical air pollution on acute respiratory symptoms in children. $\mathrm{Am} J$ Respir Crit Care Med 1995; 151: 27-32.

31. Avol EL, Linn WS, Shamoo DA, et al. Short-term respiratory effects of photochemical oxidant exposure in exercising children. J Air Pollut Control Assn 1987; 37: 158-162.

32. McDonnell WF, Chapman RS, Leigh MW, Strope GL, Collier AM. Respiratory responses of vigorously exercising children to $0.12 \mathrm{ppm}$ ozone exposure. Am Rev Respir Dis 1985; 132: 875-879. 